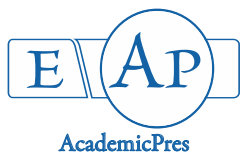

Serrano JO et al. (2021)

Notulae Scientia Biologicae 13(1):10859

DOI: $10.15835 / \mathrm{nsb} 13110859$

Research Article

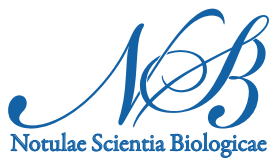

\title{
Euclidean distance: integrated criteria to study sheep behaviour under heat stress
}

\author{
Jorge O. SERRANO ${ }^{1}$, Asiel VILLARES ${ }^{1}$, Francisco D. MANUEL- \\ MALAMBA $^{2}$, Jorge MARTÍNEZ-MELO ${ }^{1}$, Carlos MAZORRA $^{1}$, \\ Ángela BORROTO ${ }^{1}$, Elliosha HAJARI ${ }^{3}$, Norge FONSECA-FUENTES ${ }^{4}$, \\ José C. LORENZO ${ }^{*}$ \\ ${ }^{1}$ University of Ciego de Ávila, Faculty of Agriculture, Ciego de Ávila,69450,Cuba; jorlay@unica.cu; asiel@unica.cu; \\ jorgemmelo@unica.cu; carlosmc@unica.cu;Niniborroto20@gmail.com \\ ${ }^{2}$ Universidad de Mandume Ya Ndemufayo, Instituto Superior Politécnico de Huíla (ISPH), Angola; fmalamba@hotmail.com \\ ${ }^{3}$ Agricultural Research Council-Tropical and Subtropical Crops, Plant Improvement, Private Bag X11208, Nelspruit, 1200, \\ South Africa; HajariE@arc.agric.za \\ ${ }^{4}$ Universidad de Granma (UDG), Centro de Estudio de Producción Animal (CEPA), Carretera de Manzanillo km 17 1/2 CP:85100, \\ Granma,Cuba; nfonsecaf@udg.co.cu \\ ${ }^{5}$ University of Ciego de Avila, Laboratory for Plant Breeding and Conservation of Genetic Resources, Bioplant Center, Ciego de \\ Ávila,69450, Cuba; jclorenzo@bioplantas.cu (corresponding author)
}

\begin{abstract}
Livestock farming with sheep represents an important income stream. With climate change, domestic sheep are being exposed to heat stress which can have adverse effects on growth. Here, data regarding sheep behaviour in response to high temperature stress was analysed using the Euclidean distance method to integrate all variables into a single representative outcome that could summarize sheep behaviour. We studied the effects of two shepherding conditions either with or without the provision of shade. The number of animals eating grass, ruminating and resting either in the shade or directly in the sun were recorded over one year at two-week intervals. As the ideal behaviour (expert's criteria), the following conditions were considered: maximum numbers of animals eating grass, ruminating and resting under shaded conditions were desirable; while the numbers of animals ruminating or resting under direct sunlight should be at a minimum. The statistical evaluation undertaken integrated these variables to identify the most significant effects of heat stress. Sheep spent most of the daylight hours engaged in eating and this activity was more intensive where shaded conditions were available. The Euclidean distance calculated for the group of animals maintained under shaded conditions was statistically lower (indicating better behaviour). Based on this, it is possible to accurately rank the treatments in terms of severity. The analysis indicates that the use of the Euclidean distance could be used to summarize a simplified outcome for observational data collected in behavioural studies in response to differing climatic conditions.
\end{abstract}

Keywords: animal physiological stress; biostatistics; climate change; heat stress; Ovis aries

Received: 30 Nov 2020. Received in revised form: 22 Feb 2021. Accepted: 55 Feb 2021. Published online: O5 Mar 2021.

From Volume 13, Issue 1, 2021, Notulae Scientia Biologicae journal will use article numbers in place of the traditional method of continuous pagination through the volume. 


\section{Introduction}

Sheep farming (also known as sheep husbandry) represents a lucrative income stream for many farmers. The industry is based on small ruminant sheep breeds (Ovis aries) that have been domesticated over time. In the global meat market, sheep meat (lamb and mutton) represents an important product (Bhatt and Abbassi, 2021). Additional products derived from sheep include milk, fibre (from wool), sheepskin and parchment from hides. Sheep meat represents one of the four most important meat categories (the others include beef, pork, and poultry). Sheep production is labour intensive, and as a result, contributes to employment, particularly in developing countries where unemployment rates are high (Karthik et al., 2021). As with any commercial enterprise, a range of sheep breeds have been developed over the years in different countries in order to allow for optimal production under the diverse environmental conditions prevalent in different countries (Medjekal and Ghadbane, 2021). Specific breeds have been adapted for conditions ranging from the northern European highlands (typified by low temperatures with high rainfall) to the humid tropics and dry conditions in Africa, Asia and Australasia. In Africa and Asia, indigenous breeds are also reared. Sheep are primarily grazing animals that feed on pasture close to the ground; however, supplementation of diets with feed is common. This also allows for provision of additional nutrients to ensure that growth is optimized. Sheep can be raised under a variety of management systems depending on the country, environmental conditions encountered and socioeconomic context (FAO, 2020).

Despite the high demand for meat products, livestock production remains a contributor to greenhouse gas emissions. This is as a result of the cumulative emissions from various stages of the value chain. Climate change as a consequence of greenhouse gas emissions, and other factors, is a global concern (Sejian et al., 2017) and has resulted in adverse weather conditions across the globe, the most prominent being increased temperatures and modifications to rainfall patterns (either high levels of rain or conversely, drought conditions). Both abovementioned phenomena affect livestock and agricultural production. In the context of animal husbandry, increased surface temperatures can lead to the development of heat stress conditions for the domestic animals. This heat stress can have negative effects not only on animal health, but ultimately on feed conversion efficiency and ultimate yield in terms of mass/output per animal. Due to the genetic variation available in the gene pool of small ruminants, some sheep breeds are available with a reported higher tolerance to heat stress than others. These breeds will have an important role to play in the coming years in the context of food security when the effects of climate change continue to be exhibited. Considering the above, it is clear that there is a need to investigate the limit of heat tolerance livestock and subsequent effects on production (Rojas et al., 2017). Hence, the current short communication contributes towards the body of knowledge on the investigating the exposure of sheep to high temperature stress.

Typically, investigations in the field of agricultural science usually involve the measurement of a series of morphological, physiological, and biochemical indicators in response to applied conditions. The resulting data is then statistically analysed using univariate tests such as the T-test, Mann-Whitney U, Analysis of Variance (ANOVA), etc. followed by post-hoc tests including Tukey's HSD, Fisher's Least Significant Difference, Duncan's Multiple Range Test, etc. (Lorenzo et al., 2015; Silva et al., 2015; Sousa et al., 2015; Cerqueira et al., 2016; Reyes et al., 2018). The abovementioned tests work for the intended purposes, however, a weakness of such analyses is that they do not account for the integration of effects of experimental treatments since each indicator is analysed independently. Besides these statistical procedures, multivariate methods such as MANOVA, cluster analysis, principal component analysis and discriminant analysis, are well known and have been used extensively in agricultural research (Ivanov, 1989).

Considering the above, we evaluated the application of Euclidean distance for data collected from trials investigating sheep behaviour in response to heat stress. Due to its usefulness, Euclidean distance has been used in a broad range of studies from pattern recognition in data from different microcomputers and quantitative characterization of different oils (Ichino, 1988), to quantification of expression patterns in genes (Tavazoie et al., 1999), intelligent control systems (Jafar and Zilouchian, 2001; Fliege et al., 2019), atmospheric studies using 
spectral identification of gases (Granahan and Sweet, 2001), information retrieval (Kogan, 2007), simultaneous selection of several agricultural traits (Gomez-Pando et al., 2009), and plant in vitro culture experiments (Lorenzo et al., 2013; Gómez et al., 2018; Villalobos-Olivera et al., 2019). However, to the best of our knowledge, the statistical application reported here has not been frequently utilized in studies of sheep behaviour in the context of climate change.

In the present study, data from a sheep behavioural study was subjected to analysis by Euclidean distance. Sheep were exposed to two shepherding conditions, viz. the first where sheep had access to shaded conditions provided by trees and the second where shaded conditions were absent. There were 12 sheep per group and the following behavioural indicators were monitored every $10 \mathrm{~min}$ : number of animals eating grass, ruminating, and resting either under the shadow of a tree (shaded) or out in the open directly in the sun (un-shaded). These activities will indicate whether provision of cooler conditions in the shade will influence sheep behaviour during feeding and resting. Data were recorded over a period of 24 days from 9:00 to 11:50 and 14:00 to 16:50 on specific days. The abovementioned data were statistically analysed with integrated variables to evaluate the most significant effects of heat stress on sheep behaviour.

\section{Materials and Methods}

\section{Biological material, experimental and sampling design}

For the current study, female sheep of the Pelibuey race (Perón, 2010) were used. Sheep were two to four years old, at reproductive growth stage with each animal weighing approximately 35 to $40 \mathrm{~kg}$. The trial was conducted over the course of one year (July 2018 - June 2019). Two shepherding conditions were evaluated, i.e. either with access to shade from trees or with no access to shade (un-shaded). A series of behavioural indicators was recorded, viz. the number of animals eating, ruminating, and resting in the shade or in direct sunlight. There were 12 sheep in each group and results were monitored at 10 minute intervals from 9:00 - 11:50 and 14:00 - 16:50 over the course of days (two days per month at two week intervals): Observations were made visually as described by Czacko (1980). When the trial was not in progress, all animals remained in pens. While animals were confined, a source of water and feed was provided which was comprised of Pennisetum purpureum (50\%), Saccharum officinarum (50\%) and sodium chloride.

\section{Description of the study site}

The trial was conducted at the "La Orlinda" farm in Ciego de Avila, Cuba $\left(2152^{\prime} 48.6^{\prime \prime}\right.$ N, 78 $41^{\prime} 32.6^{\prime \prime}$ W; 53 meters above sea level). The soil was a typical, lixiviated, yellow and quarzitic ferralytic type. Average ambient temperature conditions ranged from a minimum of $19.7^{\circ} \mathrm{C}$ to a maximum of $33.4^{\circ} \mathrm{C}$. The relative humidity was between 72 and $97 \%$ with $600-800 \mathrm{~mm}$ of rainfall per year (Meteorological Centre of Ciego de Avila Province, 2019). For the two treatments described above, the animals roamed on 2 ha of land. The main grasses that grew on this land were Paspalum notatum (45\% coverage), Bothriochloa pertusa and Dichanthium caricosum (with a combined coverage of $40 \%$ ). The remaining $15 \%$ was comprised of Sporobolus indicus and Sida rhombifolia. In order to provide shade under the experimental conditions, 10 adult trees of Casuarina esquiselifolia and five of Samanea saman were grown.

\section{Qualitative analysis and statistical procedures}

All data generated were statistically analysed using SPSS (Version 8.0 for Windows, SPSS Inc., New York, NY) to perform T-tests ( $\mathrm{p}=0.05)$. Moreover, to identify the most significant integrated effects of heat stress on sheep behaviour, the Euclidean distances to the expert's criteria were calculated. As the ideal behaviour (expert's criteria), and based on literature (López et al., 2015), the following conditions were considered: the total number of animals eating, and ruminating and resting in the shade or in direct sunlight. 
A database of observations was made in Microsoft Excel. Data were then standardized with 0 to 1 by the min-max normalization method (Kantardzic, 2003). Following identification of the min and max values for each variable, a formula was applied to standardize the data: (Value to be normalized - Min value observed in the experiment) / (Max value observed in the experiment - Min value observed in the experiment). The square difference between the standardized observed values in the treatments and the expert's criteria were then calculated. Euclidean distances were also computed.

\section{Results and Discussion}

The present study used observational data to evaluate the response of sheep to heat stress. Under the shaded conditions, trees provided shade and reduced temperatures while under the heat stress conditions, sheep did not have access to shade. Behavioural attributes relating to eating, ruminating, and resting were monitored. The results indicated that during the observational period (from 9:00 until 16:50), animals devoted most of their time to eating rather than resting (Table 1). Furthermore, animals preferred to eat under shaded conditions ( 9.9 out of 12) rather than in the direct sunlight (7.7 animals out of 12). This is not unexpected as exposure to high temperatures can affect social and feeding behaviour. Increases in body temperature could result in more energy being expended for thermoregulation ultimately leading to reduced production capacity. The lower temperatures provided by shading, avoids this scenario.

As expected, animals preferred shadow to ruminate and rest. Our results indicated that these four activities have less importance to animals compared to eating grasses (Table 1). In brief, animal behaviour seems to be better where tree shadow was available.

As discussed above, an overview of the effect of the provision of shaded conditions on sheep behaviour is depicted in Table 1. For the initial statistical analysis, each dependent variable was analysed separately, giving a broad insight into the responses induced by the treatment (i.e. provision of shade or lack thereof). However, there are inherent weaknesses with this method which limits the interpretation of the results obtained. For example, the contribution of experimental noise and the sensitivity of individual measurements can influence the analysis which will ultimately lead to challenges in using such methods to rank the treatments in terms of severity. In order to overcome these weaknesses, a more holistic analysis method is required; therefore, we combined all measurements and calculated Euclidean distances in order to integrate results (Figure 1).

Table 1. Number of animals eating grass, ruminating under shaded conditions or directly under the sun, and resting under shaded conditions or directly under the sun

\begin{tabular}{|c|c|c|c|c|c|}
\hline & Eating grasses & $\begin{array}{c}\text { Ruminating } \\
\text { under tree } \\
\text { shadow }\end{array}$ & $\begin{array}{c}\text { Ruminating } \\
\text { under sun } \\
\text { radiation }\end{array}$ & $\begin{array}{c}\text { Resting } \\
\text { under tree } \\
\text { shadow }\end{array}$ & $\begin{array}{c}\text { Resting } \\
\text { under sun } \\
\text { radiation }\end{array}$ \\
\hline $\begin{array}{c}\text { Tree shadow available: } 10 \text { adult } \\
\text { trees of Casuarina esquiselifolia and } \\
\text { five of Samanea saman in 2 ha. }\end{array}$ & $9.0 \pm 0.1 \mathrm{a}$ & $0.7 \pm 0.1 \mathrm{a}$ & $0.0 \pm 0.0 \mathrm{~b}$ & $2.0 \pm 0.1 \mathrm{a}$ & $0.0 \pm 0.0 \mathrm{~b}$ \\
\hline Shadow not available in 2 ha. & $7.7 \pm 0.1 \mathrm{~b}$ & $0.0 \pm 0.0 \mathrm{~b}$ & $0.7 \pm 0.0 \mathrm{a}$ & $0.0 \pm 0.0 \mathrm{~b}$ & $3.2 \pm 0.1 \mathrm{a}$ \\
\hline
\end{tabular}

Results with the same letter are not statistically different ( $t$-test, $\mathrm{p}>0.05)$.

(values represent average $\pm \mathrm{SE}$ ).

Figure 1a describes the method used to calculate Euclidean distances. Figure 1b shows the graphical illustration of the outcome of the calculation of the Euclidean distance from each group of animals to the expert's criteria. These results indicate that after consideration of all indicators recorded, the Euclidean distance calculated for the group of animals maintained under shaded conditions was statistically lower (indicative of better behaviour) than that of those animals under un-shaded conditions. Hence, the preferred behaviour would be for sheep to seek shaded conditions. Based on Euclidian distances relative to the ideal physiological 
status (expert's criteria); it was shown that it is possible to accurately rank the treatments in terms of severity (Figure 1b).

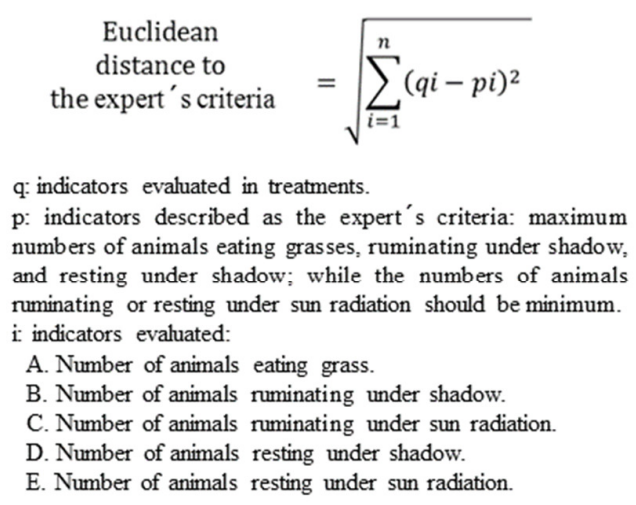

a

Figure 1. Calculation of the Euclidean distance from each shepherding condition to the expert's criteria. a. Formula to calculate the Euclidean distances. b. Averaged Euclidean distances in each shepherding condition to the expert criteria. Results with different letters are statistically different ( $t$-test, $\mathrm{p}>0.05)$. Vertical bars represent $\mathrm{SE}$. The lower the Euclidean distance to the expert's criteria, the better for animals.

Original data were standardized with 0 to 1 by the min-max normalization (Kantardzic 2003). Min and max values of each variable were identified and then the following formula was used to standardize data: (Value to be normalized Min value observed in the experiment) / (Max value observed in the experiment - Min value observed in the experiment).

After standardization of all data ( $\mathrm{n}=1728$ observations ( 24 days $\mathrm{x} 864$ observations per day $\mathrm{x} 2$ shepherding conditions (with or without tree shadow)), the Euclidean distance to the expert's criteria were calculated according to the above formula.

Prior to calculation of Euclidean distances (Figure 1a), it is necessary to standardize variables in order to prevent certain features from dominating distance determinations, simply by having large numerical values (Duda et al., 2001; Kantardzic, 2003). The following was considered as the ideal physiological status (expert's criteria) to calculate the Euclidean distances (López et al., 2015): maximum number of animals eating grasses, ruminating under shadow, and resting under shadow; while the number of animals ruminating or resting under direct radiation should be at a minimum.

By definition, the equation shown in Figure 1a implies that the Euclidian distance tends to increase with an increasing number of parameters. Hence, the number of recorded variables should be the same for all treatments and the traits measured should be quantitative. Theoretically, the number of variables that can be evaluated is limitless. Apart from assessment of Euclidean distances, there are alternative methods available that can be used to graphically demonstrate distances among treatments, e.g. Biplot metrics or non-dimensional scaling (NMDS). For multivariate data, a biplot can be used to present the different elements of a data matrix, i.e. samples are displayed as points while variables are displayed as vectors. In contrast, for the NMDS method, the goal is to display data in multidimensional space as accurately as possible using a limited number of dimensions that allows for easy plotting and visualization. The NMDS technique relies on rank orders (distances) for ordination (i.e. non-metric). The use of distances overcomes some of the issues associated with using predictor variables alone (e.g. sensitivity to transformation). The NMDS method is regarded as being flexible as it is amenable to a variety of data types (Chapman et al., 2001; Gabriel, 2002; Krzanowski, 2004; Faria and Demetrio, 2008; Blasius et al., 2009). 


\section{Conclusions}

The Euclidean distance has been extensively used in different scientific fields, but in this study has been used to integrate sheep response parameters to heat stress. The analysis indicates that the use of the Euclidean distance could contribute to establishing a more integrated evaluation of the contrasting climatic conditions. It can also be used as a non-dimensional indicator when comparing different growth environmental conditions.

\section{Authors' Contributions}

Conceptualization: JOS, JMM, CM, AB, EH, NFF and JCL; Data curation: JOS, AV and FDMM; Formal analysis: JOS, JMM, CM, AB, EH, NFF and JCL; Funding acquisition: JOS; Investigation: JOS, AV and FDMM; Methodology: JOS and JCL; Project administration: JOS; Resources: JOS; Supervision: JOS and JCL; Writing - original draft: JOS and JCL; Writing - review and editing: EH and JCL. All authors read and approved the final manuscript.

Ethical approval (for researches involving animals or humans)

Informed consent was obtained from all individual participants included in the study. Additional informed consent was obtained from all individual participants for whom identifying information is included in this article.

\section{Acknowledgements}

This research was supported by the Faculty of Agriculture and the Bioplant Centre of the University of Ciego de Ávila (Cuba, grant number 007-2019), the Universidad de Mandume Ya Ndemufayo (Angola), the Universidad de Granma (Cuba); and the Agricultural Research Council-Tropical and Subtropical Crops (South Africa).

\section{Conflict of Interests}

The authors declare that there are no conflicts of interest related to this article.

\section{References}

Bhatt A, Abbassi B (2021). Review of environmental performance of sheep farming using life cycle assessment. Journal of Cleaner Production: 126192.

Blasius J, Eilers P, Gower JC (2009). Better biplots. Computational Statistic Data Analysis 53:3145-3158.

Cerqueira JOL, Araújo JPP, Blanco-Penedo I, Cantalapiedra J, Silvestre AMD, Silva SJCR (2016). Predicción de estrés térmico en vacas lecheras mediante indicadores ambientales y fisiológicos. Archives of Zootechnique 65:357-364. Czacko J (1980). Metodología sobre diversas conductas en diferentes animales. MTA Biol Oszt Kozl 23:239-253.

Chapman S, Shenk P, Kazan K, Manners J (2001). Using biplots to interpret gene expression pattern in plants. Bioinformatic Application Note 18:202-204. https://doi.org/10.1093/bioinformatics/18.1.202

Duda R, Hart P, Stork D (2001). Pattern classification. John Wiley \& Sons Inc, New York. 
FAO (2020). Livestock systems. Retrieved 2020 October 08 from http://Www.fao.org/livestock-systems/globaldistributions/sheep/en/

Faria JC, Demetrio CGB (2008). BPCA: Biplot of multivariate data based on principal components analysis. UESC and ESALQ, Ilheus, Bahia, Brasil and Piracicaba, Sao Paulo, Brasil. R package version 1.02. http://CRAN.R-project.org/package=bpca

Fliege J, Qi H-D, Xiu N (2019). Euclidean distance matrix optimization for sensor network localization. In: Gao C, Zhao G, Fourati H (Eds). Cooperative Localization and Navigation: Theory, Research and Practice. CRC Press, Boca Raton, FL

Gabriel KR (2002). Goodness of fit of biplots and correspondence analysis. Biometrika 89:423-436. https://doi.org/10.1093/biomet/89.2.423

Gomez-Pando L, Jimenez-Davalos J, Eguiluz-de la Barra A, Aguilar-Castellanos E, Falconí-Palomino J, Ibañez-Tremolada M, ... Lorenzo JC (2009). Field performance of new in vitro androgenesis-derived double haploids of barley. Euphytica 166:269-276.

Gómez D, Hernández L, Yabor L, Beemster GTS, Tebbe CC, Papenbrock J, Lorenzo JC (2018). Euclidean distance can identify the mannitol level that produces the most remarkable integral effect on sugarcane micropropagation in temporary immersion bioreactors. Journal of Plant Research 131:719-724.

https://doi.org/10.1007/s10265-018-1028-7

Granahan J, Sweet J (2001). An evaluation of atmospheric correction techniques using the spectral similarity scale. In: IGARSS 2001. Scanning the Present and Resolving the Future. Proceedings. IEEE 2001 International Geoscience and Remote Sensing Symposium (Cat. No. 01CH37217) 5:2022-2024.

Ichino M (1988). General metrics for mixed features-the cartesian space theory for pattern recognition. In: Proceedings of the 1988 IEEE International Conference on Systems, Man, and Cybernetics 1:494-497.

Ivanov Z (1989). The agricultural experimentation. Pueblo y Educación, Havana, pp 332.

Jafar M, Zilouchian A (2001). Application of soft computing for desalination technology. In: Zilouchian A, Jamshidi M (Eds). Intelligent Control Systems Using Soft Computing Methodologies. CRC Press, Boca Raton, pp 315-353.

Kantardzic M (2003). Data mining: concepts, models, methods and algorithms. Technometrics 45:277. https://doi.org/10.1198/tech.2003.s785

Karthik D, Suresh J, Reddy YR, Sharma G, Ramana J, Gangaraju G, ... Reddy PRK (2021). Farming systems in sheep rearing: Impact on growth and reproductive performance, nutrient digestibility, disease incidence and heat stress indices. PloS One 16:e244922. https://doi.org/10.1371/journal.pone.0244922

Kogan J (2007). Introduction to clustering large and high dimensional data. Cambridge University Press, New York. https://doi.org/10.1111/j.1751-5823.2007.00030_27.x

Krzanowski WJ (2004). Biplots for multifactorial analysis of distance. Biometrics 60:517-524. https://doi.org/10.1111/j.0006-341X.2004.00198.x

López R, Pinto-Santini L, Perozo D, Pineda J, Oliveros I, Chacón T, ... Ríos de Álvarez L (2015). Confort térmico y crecimiento de corderas West African pastoreando con y sin acceso a sombra artificial. Archives of Zootechnique 64:139-146.

Lorenzo JC, Varela M, Hernández M, Gutiérrez A, Pérez A, Loyola O (2013). Integrated criteria to identify the best treatment in plant biotechnology experiments. Acta Physiologiae Plantarum 35:3261-3264. https://doi.org/10.1007/s11738-013-1352-4

Lorenzo JC, Yabor L, Medina N, Quintana N, Wells V (2015). Coefficient of variation can identify the most important effects of experimental treatments. Notulae Botanicae Horti Agrobotanici Cluj-Napoca https://doi.org/1015835/NBHA431988143:287-291

Medjekal S, Ghadbane M (2021). Sheep digestive physiology and constituents of feeds. In: Sheep Farming-An Approach to Feed, Growth and Health. IntechOpen. https://doi.org/10.5772/intechopen.92054

Perón N (2010). Manual del ovino. Pelibuey Asociación Cubana de Producción Animal (ACPA), La Habana.

Reyes J, Herrera M, Marquina J, Enjoy D, Pinto-Santini L (2018). Ambiente físico y respuestas fisiológicas de ovinos bajo sombra en horas de máxima radiación. Archives of Zootechnique 67:318-323. https://doi.org/10.21071/az.v67i259.3786

Rojas D, Nejadhashemi A, Harrigan T, Woznicki S (2017). Climate change and livestock: impacts, adaptation, and mitigation. Climatic Risk Management 16:145-163. https://doi.org/10.1016/j.crm.2017.02.001

Sejian V, Bhatta R, Gaughan J, Malik P, Naqvi S, Lal R (2017). Adapting sheep production to climate change. In: Sheep Production Adapting to Climate Change. Springer Singapore, Singapore, pp 1-29. 
Silva TPD, Marques CAT, Torreão JNC, Bezerra LR, Araújo MJ, Gottardi FP, ... Oliveira RL (2015). Ingestive behaviour of grazing ewes given two levels of concentrate. South African Journal of Animal Science 45:180-187.

Sousa L, Maurício R, Paciullo D, Silveira S, Ribeiro R, Calsavara L, Moreira G (2015). Forage intake, feeding behavior and bio-climatological indices of pasture grass, under the influence of trees, in a silvopastoral system. Tropical Grasslands-Forrajes Tropicales 3:129-141. https://doi.org/10.17138/TGFT(3)129-141

Tavazoie S, Hughes J, Campbell M (1999). Systematic determination of genetic network architecture. Natural Genetics 22:281-285. https://doi.org/10.1038/10343

Villalobos-Olivera A, Hernández L, Martínez J, Quintana N, Zevallos BE, Yabor L, ... Sershen JCL (2019). Euclidean distance can recognize the Biojas concentration that produces the ideal physiological status of pineapple in vitro plantlets. In Vitro Cellular and Developmental Biology-Plant 56(2):259-263.

https://doi.org/101007/s11627-019-10023-5

OPEN ACCESS

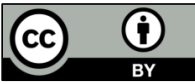

The journal offers free, immediate, and unrestricted access to peer-reviewed research and scholarly work. Users are allowed to read, download, copy, distribute, print, search, or link to the full texts of the articles, or use them for any other lawful purpose, without asking prior permission from the publisher or the author.

License - Articles published in Notulae Scientia Biologicae are Open-Access, distributed under the terms and conditions of the Creative Commons Attribution (CC BY 4.0) License.

(c) Articles by the authors; SHST, Cluj-Napoca, Romania. The journal allows the author(s) to hold the copyright/to retain publishing rights without restriction. 